Article

\title{
Stories of Snow and Fire: The Importance of Narrative to a Critically Pluralistic Environmental Aesthetic
}

\author{
John Charles Ryan
}

School of Communications and Arts, Edith Cowan University, 2 Bradford Street, Mount Lawley, WA 6050, Australia; E-Mail: jryan9@our.ecu.edu.au; Tel.: +61-08-9370-6454

Received: 8 January 2013; in revised form: 19 February 2013 / Accepted: 12 March 2013 /

Published: 21 March 2013

\begin{abstract}
Written narratives enable humans to appreciate the natural world in aesthetic terms. Firstly, narratives can galvanize for the reader a sense for another person's experience of nature through the aesthetic representation of that experience in language. Secondly, narratives can encode and document for the human appreciator as writer an experience of nature in aesthetic terms. Through different narrative lenses, the compelling qualities of environments can be crystallized for both the reader (who vicariously experiences nature through language) and the human appreciator (who directly experiences nature through the senses). However, according to philosopher Allen Carlson's "natural environmental model” of landscape aesthetics, science provides the definitive narrative that represents nature on its own terms and catalyzes appropriate appreciation. In this article, I examine Carlson's claim and argue for an environmental aesthetic philosophy of narrative multiplicity. Such a model would draw from scientific, indigenous, and journalistic narrative modes toward a critically pluralistic environmental aesthetic of the natural world. The ethical framework I propose- the function of which I characterize simply as narrative "cross-checking"-acknowledges the value of narrative heterogeneity in expressing and generating aesthetic experience of environments. This article's thesis is forwarded through extensive treatment of these three narratives expressed within two examples, one of geographical place and one of environmental practice. As I will suggest, Denali, the prominent Alaskan mountain, can be aesthetically appreciated through the diverse narratives enumerated above. As a second case study, the traditional burning regimes of indigenous peoples reveal collectively how a critically pluralistic environmental aesthetic of narratives can be applied to-and identified to exist within-ecocultural practices, such as firing the landscape.
\end{abstract}


Keywords: narratives; ecology; environmental aesthetics; Denali; traditional burning

\section{Introduction: Stories of Snow and Fire}

Denali presides above the Alaskan interior, its ermine coat of snow contrasting with the verdant basin below (Figure 1). The angularity of its bulk contrasts noticeably with the undulating green valley of the foreground. Unlike higher counterparts in the ranges of Nepal that compete for prominence in the skyline, Mount McKinley (the European name for Denali) protrudes starkly from the Alaskan flatlands as a kind of solitary monarch of the subarctic Alaskan vista. On a radiant early summer day, Denali's glaciers glisten-opaque, milky ice interspersed with dark skeins of granite. To consider Denali as merely a scene framed for our sensual pleasure, however, is to dismiss the manifold aesthetic experiences that the natural world-including mountainscapes-affords us. Indeed, aesthetic experience of the environment is generated by multifarious human faculties, including the bodily senses of touch, taste, and smell; our emotion, imagination, and intuition; as well as scientific, indigenous, and folkloric knowledge of places, such as the mountain Denali.

Figure 1. The highest peak in the United States, the name Denali comes from the Koyukon Athabaskan language for “The High One.” The mountain has an elevation of 20,320 feet (6,194 $\mathrm{m}$ ) above sea level (Image Source: Wikipedia).

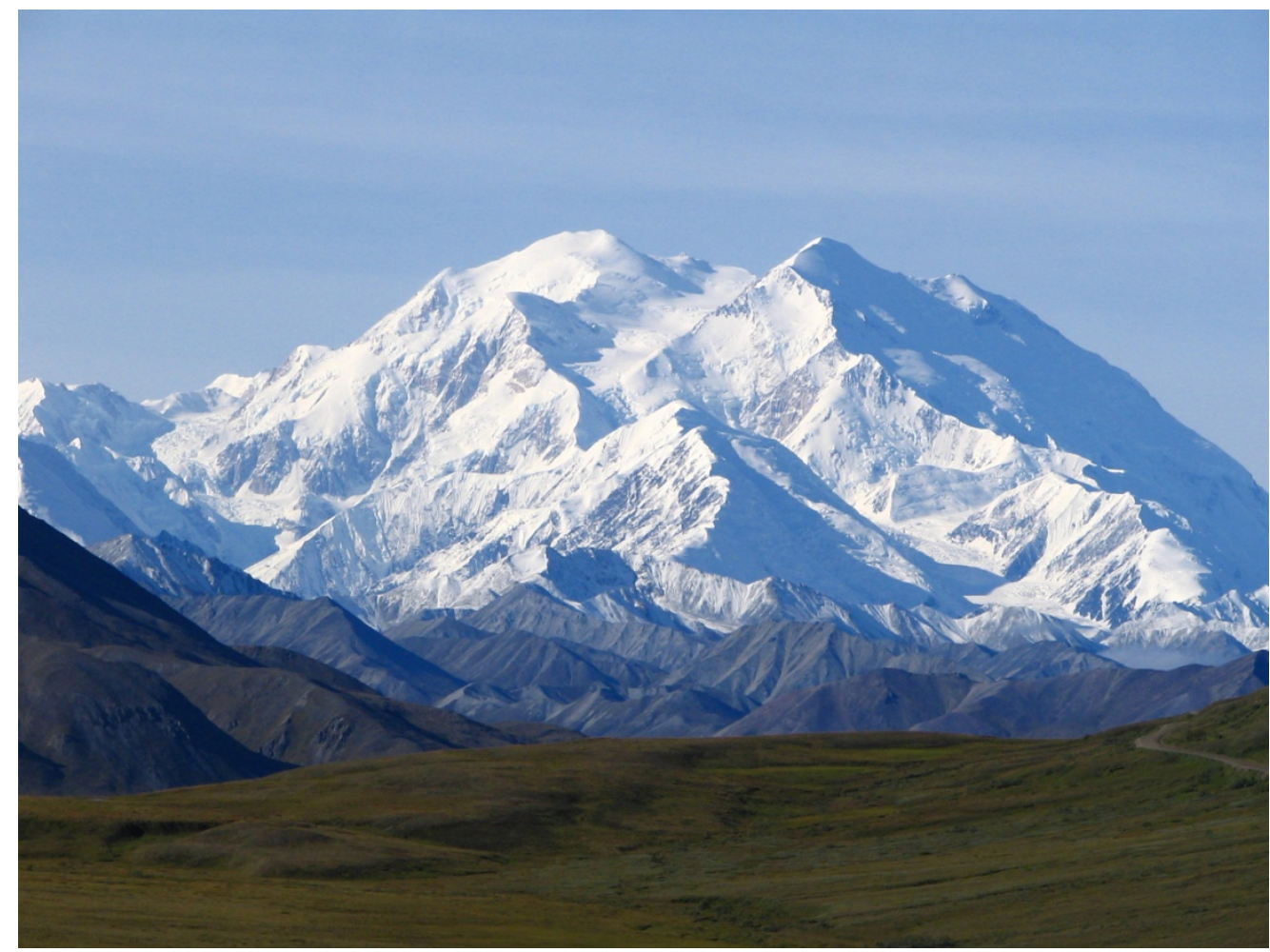

Indeed, the immediate visual characteristics of the mountain-the glistening snow and the angularity of rock — can serve as a picturesque basis for a more nuanced, layered, and sensorial mode of appreciation. For instance, through our imagination, we could project into time and attach possibilities to the mountain; envisioning summer brings greater attention to the rock features 
underlying the snow pack, along with the wilderness background and pellucid blue sky. Moreover, we could physically encounter the mountain, calling on other sensory faculties and stimuli-for example, the numbing chafe of wind on our cheeks; the smell of evergreens; or kinetic sensations of muscle fatigue and accelerated heart rate. Additionally, in heightening our aesthetic experience of Denali, we could reflect on its natural history: the mountain's narrative detailing the geological events responsible for the aesthetic qualities of the scene it imprints within our perception. For the purposes of this article, it is the role of scientific, indigenous, folkloric, and popular narratives as catalysts for aesthetic experience of the natural world that preoccupies a critically pluralistic environmental aesthetic based on narrative heterogeneity.

In a similar vein, in the boreal forests of northern Alberta, anthropologist Arthur Bailey, as depicted in the film The Fires of Spring (1978), stands beside train tracks that strike through the landscape [1]. Prairie parkland, punctuated with willow and aspen, unfolds to the west. This is the land beheld in 1903 by the drafters of Canadian title to this region, a boreal mosaic of grasslands - forest studded with patches of muskeg-whose productive soils attracted European settlers. This is also the land frequently burned by the railroad authority to maintain unobstructed train lines-a scenario existing in many places in the world [2]. To the western side of the tracks, a different situation prevails: aspen forest dominates the plant community where fires have been absent for several decades. In fact, the boreal forest of northern Alberta had an open configuration before provincial bans on burning were enacted in the early 1900s [3]. Traditional firing in the spring induced an early spurt of succulent herbs and shoots, and maintained a more uniform growth of the prairie, creating the preferred habitat for the animals on which the indigenous Dene people subsisted. Monikers like "High Prairie," however, are now anachronisms, hinting of a time when frequent, light spring burning maintained an expansive prairie mosaic. The muskeg and forest pattern, which also provided grazing for moose and other herbivorous animals, has been altered by unconstrained growth of brush and trees. Importantly for the focus of this article, the aesthetic qualities of the prairie landscape have been altered by the exclusion of burning practices.

The traditional burning of an ecosystem is a significant component of ecological management in indigenous practices today. Historically, burning has been a vital survival strategy with a broad range of purposes, the most salient of which is the ensuring of continued access to subsistence resources. Frequent, low-intensity, and patchy firing of the land, in conjunction with restrictions of such practices in select areas, influenced the composition of ecosystems by promoting the growth of resource plants and inhibiting the predominance of less desirable plant species. Examples from North America, Australia, and Africa collectively express the technological sophistication of indigenous management of the land through a burning regime implemented and designed specifically for the weather, season, biota, and culture of a place. The termination of traditional fire management systems has resulted in discernible alterations in biotic composition through the suppression of fire-sensitive species and the encouragement of fire-promoting plants, such as grasses. The relatively new field of fire ecology now provides us a wealth of knowledge and perspectives for understanding the distinctive cultural ecology of human-made fires ([3], p. 402). The incorporation of traditional fire technology into contemporary ecosystem management paradigms has become increasingly commonplace.

Yet, just as our appreciation of Denali is enhanced by the many stories surrounding the mountain, the emerging field of fire ecology could benefit from ongoing engagement with the diverse narratives 
of indigenous burning practices, not only those forwarded by managerialist conservation science. Indeed, some of the narratives of indigenous burning practices involve spiritual and cultural meanings linking landscapes, people, and stewardship. For example, in Aboriginal Australia, as anthropologist Deborah Bird Rose observes in Nourishing Terrains, "when Aboriginal people speak English, they describe their burning practices as 'cleaning up the country'. There is a well defined aesthetic; country which has been burned is country which looks cared for and clean. It is good country” [4]. Hence, the story of the burned landscape, for Aboriginal Australians, is closely linked to a socio-environmental condition of long-term regeneration. In a traditional sense, caring for country is connected to an appropriate aesthetics of burning, ensuring the long-term viability of the land. Moreover, Aboriginal stories of burning the landscape also implicate the spirits of deceased ancestors; and hence narratives of fire are also narratives of family and kin. An aesthetics of caring for country, therefore, is a broader ecocultural aesthetics based in stories. John Bradley reports:

For the Yanyuwa the burning of country is an important way of demonstrating a continuity with the people who have died, their ancestors, or li-wankala, 'the old people'. The spirits of these people are said still to inhabit the landscape; they still hunt, sing, dance and are said even to still burn the country. Indeed it is spoken by the contemporary old people that before the coming of the white people, the spirits of the deceased kin would set fire to the country themselves for hunting, and up to quite recently, country that was burnt was left for several days so the spirits of the deceased could hunt first ([4], p. 71).

Bradley goes on to say that "country that has not been burnt for a long time is described as being 'shut up'. Visually this can be seen by the increase in the understory vegetation, and on the islands by the increase of choking vine thickets” ([4], p. 72). The park-like, picturesque appearance of the Australian landscape in many places, as noted in the journals of numerous nineteenth-century visitors and explorers, resulted from the burning regimes of Aboriginal peoples. Considering the meeting of both narratives, we see the convergence of a techno-scientific European aesthetics of colonialism and a regenerative indigenous aesthetics of caring for country as a "nourishing terrain" [4].

Stories, such as these provided by scientists, anthropologists, and indigenous peoples, satisfy our collective needs for understanding what we perceive and experience in nature. As such, stories can be enduring foundations for the appreciation of the natural world. Moreover, narratives (used here interchangeably with the word "stories") can determine the qualities and tones of our aesthetic experiences. They balance and moderate immediate sensory reactions to aesthetic features, such as the jaggedness of Denali or the burning of the Australian landscape, ensuring that our appreciative responses to the natural world are appropriate and continuing. Three narrative forms-scientific, indigenous, and popular/journalistic — will be discussed through the examples of snow and fire. I argue that "cross-checking" between narrative forms is indispensable for establishing the environmental appropriateness of our aesthetic responses. Narrative heterogeneity, I argue, is a component of a critically pluralistic environmental aesthetic. A broad basis for an environmental aesthetics emerges when different narrative modes commingle. The purpose of this article is to point to the need for narrative commingling. Guiding this discussion, Denali and the firing practices of different indigenous cultures will provide tangible examples of how narrative heterogeneity can deepen appreciation of the natural world as part of a sensorially refined, ecologically appropriate, and broadly attuned human aesthetic. I acknowledge that my example related to snow focuses on Denali whilst my examples 
related to fire address indigenous burning practices from around the world. Indeed, a more balanced presentation of evidence would integrate narrative examples from other prominent and well-storied peaks around the world, such as Mount Everest and Mount Kilimanjaro. Despite this limitation, which should be addressed in further studies, in broad terms an integrated philosophy of environmental narratives is significant because it responds to the current context of climate change in which conflicting accounts populate the media-from scientific corroboration of broad-scale climatic perturbations to the emotionally-charged voices of climate change skeptics; and from the place-based experiences of indigenous peoples in polar regions facing environmental threats to their small settlements to the incomprehensible scale of atmospheric transformation and the demise of planetary life-support systems. Specifically, more frequent fires in the arid regions of the United States and Australia, along with the shrinking of Alpine glaciers in Europe, heighten the implications of these two case studies: of snow and fire.

\section{Science as Narrative: Carlson’s Natural Environmental Model}

Science provides one of many narratives for aesthetically contemplating Denali and fired landscapes. Specifically, the mountain's geological story articulates those forces and events that coalesce in its present topographical form. Geology explains that Denali is primarily granitic and consists of igneous rock - forming a batholith — that collided with various plates during the formation of North America. The uplift of this batholith resulted from continued tectonic collision. The high altitude of Denali results from its position at the boundary between the Pacific and North American plates. Here, subduction, where one plate goes under the other, and strike-slip motion both occur and continue to propel Denali upward. Of course, much of the scenery in Denali is presently being shaped by a number of active glaciers [5]. In sum, geology presents the aesthetic subject with a narrative expressing the dynamism of the natural world over time. The object of aesthetic concern-the mountain —is linked to companion objects in the landscape through geological narratives.

Through narrative, we come to know the characters and protagonists (the massive batholiths, the even more colossal plates, and the glaciers, as well as our central protagonist, Denali) and the dramatic forces shaping their interactions (the titanic force of plates colliding and the strident scraping of ice against granite). Consequently we can experience the denouement of a kind of plot tension: the relatively abrupt uplifting of Denali into its present high-altitude position. An aesthetic appreciation of Denali stems from its characterizations within the geological narrative: the massiveness of the plates; the somber, heavy tone of the word "batholith;" and the deep sense of geological time involved in all of these transactions. In order to forge a pluralistic environmental aesthetic, elements of the geological narrative would intermingle with my subjective perception of Denali's aesthetics to produce an integrated response, one which is representative of Denali as a living place. In such a sense, science provides the story which enhances — rather than dictates or dominates-our regard for and appreciation of the mountain.

Allen Carlson purports the use of science as the single "appropriate" narrative for aesthetic appreciation of the natural world through his "natural environmental model.” As the essential narrative for an environmental aesthetic in Carlson's view, science "is a paradigm of that which reveals objects for what they are and with the properties they have” [6]. Carlson asserts that Mannison's position- 
nature does not have a capacity for aesthetic appreciation because it lacks the artistic design or intention of an artist-is only true where the design approach of paradigmatic art appreciation is imposed on environmental aesthetics. According to Carlson's argument, awareness of Denali's scientific narrative of logic is an underlying constituent of our appreciative response.

Here, Carlson discerns between "design” and "order" appreciation. He argues that the aesthetic experience of the natural world must break free of design theory in which an object is regarded for its immediate phenomenological presence, apart from the history it bears. This approach tends to exclude relationships between animate and non-animate members of landscapes. Carlson moves toward order appreciation by describing avant-garde and anti-art works such as Jackson Pollack's drip paintings (spontaneity and chance), Duchamp's Dadaist "found art" (emphasis on the selective process of the artist) and Dali's Surrealist painting (juxtaposition of disparate images, colors, and textures). These works, for Carlson, prioritize the story behind the object over the design principles exhibited through the object; for instance, the artistic essence of a toilet bowl on display reflects the reasoning of the artist encapsulated in a narrative, describing where the object was found, why it was chosen and perhaps what political or intellectual events the artist responded to. Carlson terms this "order appreciation.” In contrast to design appreciation, these works exhibit an ordered pattern and thus their appreciation will be different: "The object embodying the design no longer embodies design [but the discerning of order] and the individual who embodies the design is no longer a designer [a selector or distinguisher, instead]” ([6], p. 221). According to Carlson, avant-garde artworks, by embodying order appreciation, present a possible model for an environmental aesthetics.

Carlson proposes that, in the appreciation of order, we should look for the narrative behind the genesis of the work. While the story behind an ordered artwork, such as Pollack's drip painting, is the particular technique or circumstances inscribed within it, an analogous framework for environmental aesthetics is natural science. The natural order of science makes the pattern comprehensible and appreciable, as design does for a designed object. The objects or landscapes embodying the order are informed by natural forces. The relevant forces of nature are analogous to the artist's narrative of how or why an artwork came into existence. For Carlson, science is the essential narrative for aesthetic experience of nature; through extrapolation, the authenticity of one's appreciation of ordered environmental phenomena depends upon one's understanding of and engagement with natural science.

Hence, the "natural environmental model” prioritizes scientific knowledge in the aesthetic judgment of the natural world. Here, natural history assumes the position of the artist in ordered artworks by revealing the story behind the creation. Science is emphasized over other narrative forms because of its inherent objectivity. Furthering Carlson's argument, Marcia Eaton supports the exclusivity of science as the appropriate narrative for natural aesthetics: "In the case of aesthetic appreciation of nature, the scrutiny is based upon and enriched by scientific understanding of the workings of nature; without that one cannot be certain that one's response is to nature and not to something else” [7]. The connection between science, objective knowledge of nature, and truth formation prompts cognitive theorists such as Carlson and Eaton to extend a priori confidence to disciplines like geology and fire science in countering subjective falsehoods-those assessments deemed irrelevant or inappropriate to aesthetic appreciation of the natural world. 


\section{Returning to Denali: Indigenous Cosmology as an Appropriate Narrative for Aesthetic Appreciation of Nature}

The Koyukon Athapaskan, who can trace their presence in the northwest interior of Alaska 1,500 years back, explain the presence of Denali in their corpus of stories called the "Distant Time:"

The Raven, incarnated as a young man, had paddled his canoe across a great body of water to ask a woman to marry him. She refused to be his wife, so he made her sink into the mud and disappear; and then he began paddling back home. The woman's mother kept two brown bears, and in her anger she told them to drown the young man. They dug furiously at the lake's edge, making huge waves everywhere on the water. But Raven calmed a narrow path before him and paddled on. Eventually he became exhausted, so he threw a harpoon that struck the crest of a wave. At that moment he fainted from the intensity of his concentration, and when he awoke a forested land had become a small mountain. Then it had glanced off, eventually striking a huge wave that solidified into another mountain-the one now called Deenaalee, or Mount McKinley [8].

This Koyukon narrative of Denali's genesis suggests the importance of indigenous knowledge in aesthetic appreciation. An aesthetic subject could become enthralled by the image of a wave solidifying to become a mountain. The image and story account—as successfully and appropriately as natural science - for the cascading features of the mountain, waves frozen in a tense energetic moment before crashing to the lake. Raven's spear becomes a protracted line of rock extending from the summit. For a critically pluralistic aesthetic, these images of ice and cascades are sufficient enough to initiate an aesthetic response to the mountain. Thus, the success of this kind of indigenous narrative in stimulating an aesthetic experience contests Carlson's claim that natural science, and its commonsense predecessors and analogues, have unequivocal standing over aesthetic appreciation of the natural world.

Thomas Heyd demonstrates that there are key problems with the "natural environmental model." He argues that aesthetic appreciation should benefit from diverse narratives, developed by equally diverse cultures across the globe. Moreover, for Heyd, scientific knowledge can be counterproductive to our aesthetic experience because "it directs our attention to the theoretical level and the general case, diverting us from the personal level and the particular case that we actually need to engage” [9]. Heyd explains that scientific knowledge, in its capacity to universalize, can fail to account for particularities of a specific natural object or landscape, such as a mountain or burned landscape. However, these particularities are essential for an aesthetic response most representative of a certain tree, mountain, or ecosystem. In the case of Denali, the geological narrative fails to express the subtle, human-scale chasms and protuberances - those aesthetic characteristics which distinguish Denali from other mountains on the planet.

Proponents of the exclusivity of scientific narratives tend to discredit the role of indigenous knowledge in the aesthetic experience of the environment. The alleged incompatibility between scientific understanding and indigenous knowledge reflects a modern dichotomy over the existence of truth, which, crudely put, permeates many facets of Western (and Westernized) cultures and extends into environmental aesthetics. Anthropologist Eugene Hunn comments that "in America today a 'myth' is a species of falsehood. For Indians [Native Americans], myths were and are a species of truth” [10]. The disregard for indigenous cosmology and other forms of "folkloric" knowledge as a 
legitimate basis for aesthetic experience, is part of a broader marginalization of non-scientific knowledge, and, conversely, a fuller investment in scientifically-dictated epistemology. Environmental philosopher Holmes Rolston, although he doesn't overtly discredit folkloric knowledge, considers the custodial role of science over myth: "Science is necessary to banish ('deconstruct') these myths, before we can understand in a corrected aesthetic” [11]. Similarly, Carlson dismisses folkloric and indigenous knowledge in favor of science, although he does so tactfully and tacitly: "Thus, perhaps nature is easiest to appreciate when our account of it is simplistic anthropomorphic folklore: a story of almost human gods or godlike human heroes not unlike the so-called primitive peoples who are said to feel exceptionally close to nature...to appreciate nature is to confront either an almighty god or blind natural forces by way of ourselves... it is no surprise if typically only the confrontations with nature are marked by overwhelming wonder and awe” ([6], p. 223). For Carlson, mythical creatures are not credible; folklore is an indirect, culturally-specific and therefore less verifiable (universalized) source for experience of the natural world. Again, science is the primary leveler for aesthetic experience of the natural world. For these theorists, science makes possible a genuine natural aesthetic through objectivity and freedom from non-scientific cultural imagination.

Heyd acknowledges the criticism of folklore as subjective, culturally-based, and value-driven rather than objective, universal, and value-free. He argues that the credibility of cosmological entities is irrelevant to the capacity of such stories to guide and modulate the aesthetic appreciation of the natural world. For Heyd, stories like the Dreaming of Australian Aboriginal peoples-because of their specificity and concreteness - pull us, so to speak, into the natural scene, object, or event, in a manner equally compelling to science: "[the Aboriginal Dreamtime stories illustrate] well the details in the landscape that may become perceptually salient through knowledge of it, much in analogy to the manner in which a rock face might become perceptually salient for someone knowledgeable of the geological story concerning its different strata” ([9], p. 133). As Heyd claims, scientific abstraction and universalization can divert our serious consideration of the inimitable features of certain natural phenomena. Yet, the narratives of indigenous cultures can channel our attention to the uniqueness of natural phenomenon, endemic to the geographical region of the ecocultural milieu that generated the story. Understanding the limitations of all narratives, Heyd offers the following caveat: stories need to be evaluated on an individual basis for the level to which they accentuate or obfuscate aesthetically appreciable characteristics of the natural world.

Yuriko Saito extends moral terms to Heyd's principle of narrative multiplicity. For Saito, morally appropriate narratives are those that acknowledge the reality of nature apart from human society, thereby producing a fair representation of nature. In Saito's view, the power of folklore to engage aesthetic appreciation of the natural world depends on the "degree" of the narrative. Creation myths, as universalistic narratives, attempt to account for the existence of the whole Earth, and do not provide a suitable framework for the valuation of specific mountains, rocks, or animals. For Saito, these are morally unacceptable because they fail to reflect the individual history of natural features appropriately. Bioregional narratives, on the other hand, represent the polar side of the narrative spectrum where specific attention can be given to individual attributes of objects. Such stories, exemplified by the Koyukon myth of Deenaalee, have the moral capacity to provide an appropriate environmental aesthetic according to the degree to which they express the bioregional history of the aesthetic "object." Saito explains that "the more specific the observation and attention become (as in 
bioregional narratives), the more sensitive we are to the diverse ways in which natural objects speak about their respective histories and functions through their sensuous qualities” [12]. Across diverse narratives, for Saito, the framework guiding what constitutes a morally appropriate environmental aesthetic is the degree to which the story represents nature on its own terms. Saito's terms constitute a bioregional framework for narrative environmental ethics.

\section{As With Ice, So With Fire: Science and Stories of Burning in Aboriginal Australia}

The discussion of Denali and the appreciation of its aesthetic qualities points to a critically pluralistic environmental aesthetic encompassing science and indigenous cosmologies. I now turn to a treatment of the diverse narratives that can inform the appreciation of fire, beginning with scientific interpretations of Aboriginal Australian landscape burning practices and their relevance to contemporary ecosystem management. To begin with, there is an abundance of scientific literature on Aboriginal Australian fire regimes, probably due to the relatively undisturbed continuance of traditional burning technology in the northern regions of the country. On the whole, such scientific narratives of burning strongly construct the aesthetic appreciation of fire as a utilitarian phenomenon to be controlled or an unnatural occurrence to be avoided. On an ecosystem management level, the absence of Aboriginal landscape burning in remote areas has resulted in intense seasonal fires. Growing scientific evidence reveals that the present pattern of landscape burning is deleterious to the ecological health of large areas of the Australian savanna, causing species extinction, devastation of fragile habitats such as rainforests, and degradation of ecosystem processes such as carbon sequestering and soil fertility [13]. In the absence of sustained human intervention, periodic large and high intensity wildfires offer broad-scale change in the condition of the vegetation and its associated biota.

An example of Australian indigenous burning and ecosystem management comes from the northern Kimberley region, located in the far northwest of Western Australia. Like the rest of the Australian monsoon tropics, the vegetation of the area is tall-grass Eucalyptus savanna [13]. If this terrain goes without burning for a few years, spinefex grasses (Triodia spp.) mature into large hummocks and become resinous [13]. Burning the spinefex at an early stage is vital to encourage the emergence of fresh new shoots instead of the development of clustered old plants, which yield a resin that makes kangaroos sick [13]. In the absence of periodic burning of the savanna, the establishment of other tenacious weeds, such as Gamba grass, can cause the fires to achieve an intensity that destroys important trees [13].

Scientific research into fire systems indicates that a shift in the spatial scale of fires has resulted in the loss of fire sensitive flora and the preponderance of fire-promoting grasses [14]. Lowland savannas, mostly dominated by native annual sorghum, annually accrue significant fuel loads capable of sending extensive fires into sensitive vegetation areas such as those of escarpments ([14], pp. 336-37). Such conflagrations accumulate enough fuel one to three years after the last fire, a period much shorter than is required for regeneration of many obligate seeders that need complete protection from fire from seedling establishment to achievement of reproductive maturity ([14], p. 337).

Dukaladjarranj, a clan estate in north-central Arnheim Land in the seasonal tropics of northern Australia where Aboriginal occupancy has been close to continuous, demonstrates the connection between firing the landscape, traditional management objectives, and ecosystem/floristic composition. 
Annual sorghum, the major contributor to dangerous fuel load levels elsewhere in the savanna, is all but absent ([14], p. 337). Furthermore, a high frequency of healthy stands of Cypress pine (Callitris intratropica) in areas that had been recently fired indicate the beneficial effects of patchy, low intensity fire ([14], p. 337). Sustained Aboriginal management and fire use in Dukaladjarranj has imposed a regime of contained, high incidence, and low intensity disturbance, to which the modern biota are exceedingly resilient ([14], p. 337).

In western Arnheim Land, traditional fire management is also effective in managing the landscape [15]. Aboriginal burning practices here, like those of other clans in remote parts of northwestern Australia, are related to such considerations as the habitat types and resources involved and the faunal relationships between habitats [16]. Regular burning of floodplains kept fuel loads low, especially where slow burning peat fires or mulurr would burn until hindered by rains [15]. Mulurr was used to control thick stands of native hymenachne (Hymenachne acutigluma) and to promote the growth of valued food plants such as water chestnut (Eliocharis spp.) [15]. Burning of floodplain grasses might have restrained natural rainforest development [15].

The south and central areas of the west coast of Australia provide further instances of traditional burning technology and ecosystem management, particularly related to the concentrated use of "fixed patch" root crop resources [17]. Burning of the country provided access to some resources such as yam (Dioscorea hastifolia) that were carefully preserved in unburned areas and encouraged others like zamia (Zamia spp.) and pasture grasses ([17], p. 143). Aboriginal burning established a mosaic pattern of open country and thick brush, creating zones of easy travel, and opening up access to the western coastal plain and eastern woodland margin ([17], p. 143). The selective use of fire, in conjunction with the knowledge of how and when to employ burning and where to limit it, made possible an elaborate subsistence system of burned and preserved areas.

In Tasmania, $240 \mathrm{~km}$ from coastal Australia, some of the rainforest and alpine environments of south-west Tasmania's World Heritage Area have been in decline due to an increase in the incidence of fires [18]. Furthermore, some of the buttongrass (Gymnoschoenus sphaerocephalus) moorland hummocks that depend on the region are threatened because of a decreased incidence and size of burns ([18], p. 195). Eucalypt forest (Eucalyptus spp.), tea-tree scrub (Acacia spp., Banksia spp., Leptospermum spp., and Metaleuca spp.) and buttongrass moorland in south-west Tasmania are products of a fire regime consistent enough to prevent the successional process that terminates in rainforest ([18], p. 195). The regime utilized by indigenous people to maintain these ecosystems in south-west Tasmania was one of frequent and probably relatively low-intensity fires ([18], p. 196).

In the Victoria River valley of the Northern Territory, Yarralin land managers are guided in their interactions with country through the notion of punya [19]. Punya refers to human actions which make everything "come up new and fresh," make "the country happy," and make "the country clean and good" [19]. Punya also points to nurturing the land to allow for good hunting conditions, abundant kangaroos and wallabies, and the seasonal regeneration of flora and fauna. A vital aspect of caring for country in the Yarralin view is traditional burning. As Deborah Bird Rose comments, the firing of the landscape is part of a larger cultural narrative: "This is a cyclical process in which the knowledge and care which humans put into the system, including the former deposition of bones, form an essential part of human survival in the system, making people, other species, and country punya” ([19], p. 101). Moreover, Rose cites an unidentified Aboriginal correspondent in Nourishing Terrains as correlating 
devastating bushfires with lack of frequent low-intensity burning: "Big fires come when that country is sick from nobody looking after with proper burning” ([4], p. 66). Hence, the narratives spoken by Aboriginal peoples themselves, suggest the centrality of firing practices to cultural and spiritual sustenance.

\section{The Role of Journalistic Narratives in Popular Appreciation of Fire and Ice}

As a narrative form linked to the aesthetic appreciation of the environment, a journalistic account will refer in this section to diaries kept by explorers, adventurers, and homesteaders, for example, or press depictions of the natural world - a corpus of which has emerged during the last thirty years due to public fascination with mountaineering and public horror over wildfires out of control, especially in Australia. Journalistic accounts-either as the historical representations in the diaries of an explorer or as contemporary works by environmental writers - are distinct genres of narrative, typically evolving out of the contemplations of an individual. Journalistic depictions of the natural world are important to consider in relation to environmental aesthetics because they intrinsically weave together subjective impressions, universalizing theories, science-based statements of an environment's history, and the social and cultural implications of events like wildfires. As such, a personal story can become part of natural history. For example, consider the following passage from the journal Alfred H. Brooks, who in 1902 became one of the first Europeans to ascend Denali:

Climbing the bluff above our camp, I overlooked the upper part of the valley, spread before me like a broad amphitheatre, its sides formed by the slopes of the mountain and its spurs. Here and there glistened in the sun the white surfaces of glaciers which found their way down from the peaks above. The great mountain rose 17,000 feet above our camp, apparently almost sheer from the flat valley floor...I found my route blocked by a smooth expanse of ice. With the aid of my geologic pick I managed to cut steps in the slippery surface, and thus climbed a hundred feet higher; then the angle of slope became steeper, and as the ridge on which the glacier lay fell off at the sides in sheer cliffs, a slip would have been fatal. Convinced at length that it would be utterly fool-hardy, alone as I was, to attempt to reach the shoulder for which I was headed, at 7,500 feet I turned and cautiously retraced my steps, to find the descent to bare ground more perilous than the ascent [20].

The abrupt contrast between the flat valley floor and the sheer verticality of the mountain is expressed eloquently in the image of an amphitheater, which further suggests the imminent drama of ascent. The "dome-shaped summit" and "upper slopes...white with snow" make appreciable the aesthetic properties of the mountain. One can take on the perspective of the speaker, standing at the base of Denali, head hyper-extended in order to take in the height of the massive mountain. The immense landscape overwhelms the explorer; expanses of ice and loose talus complicate walking; its features seem to engulf him. Additional efforts would be "fool-hardy." Thus, the reader gains an impression of Denali that combines detailed representation of aesthetic qualities with overtly personal expressions of awe and fear.

Unlike the codified language of science and the culturally specific narratives of indigenous peoples, the prosody of journalistic accounts blends individual impression with perceivable aesthetic qualities and often some regard for scientific knowledge. Yi-Fu Tuan appraises this distinguishing aspect of journalistic accounts of nature in the diaries of arctic and desert explorers where the confrontation of death in extreme climates often permeates the prose. For instance, polar explorer Fridtjof Nansen 
couples the beauty and splendor of Arctic ice with death: "Unseen and untrodden under their spotless mantle of ice the rigid polar regions slept the profound sleep of death from the earliest dawn of time” [21]. By contrast, Richard Byrd's language was more optimistic but occasionally drifted into a funereal tone: "A funereal gloom hangs in the twilight sky. This is the period between life and death. This is the way the world will look to the last man when it dies” ([21], p. 153). As quoted by Tuan, Byrd also aligned the pulsing of the aurora with classical music: "So perfectly did the music seem to blend with what was happening in the sky" ([21], p. 153). The boundary between the inner world of sensation and the external domain of aesthetic objects becomes blurred in extreme environments, according to these accounts.

The effectiveness of journalistic accounts in prompting an aesthetic response to the natural world lies in their ability to draw aesthetic subjects into the scene, through the tangibility of the language and the identifiability of human emotional and psychological responses. In this context, Heyd's discussion of environmental perception and narrative is germane [9]. The detailed treatment of a natural object or scene laden with individual impressions invites us to ponder the aesthetic properties put forth by the narrative, selecting those that we can employ in our own responses to nature. Saito's moral imperative of appreciating nature on its own terms without distortion or falsification guides us in opting for certain aesthetic features within the journalistic narrative. For example, we have the choice to infuse our aesthetic response to arctic environments, as described in Nansen's journal, with the same overtone of death and severity. Whether we decide to include the element of foreboding in an aesthetic reaction to the perceptual features of ice or rock depends on the level of our intention to represent the environment fully and appropriately. Furthermore, we can choose to consider Denali an amphitheatre in order to appropriate the juxtaposition of horizontal and vertical features for our aesthetic benefit. Additionally, we could choose to see burnt country as cared for or as devastated, depending on the degree and severity of our sensory intake. I emphasize choices here, with regard to all three narratives discussed so far, because a critical aspect of aesthetic appreciation of the natural world depends on what we decide to use as the substances of aesthetic meaning-making. I argue that a form of aesthetic cross-referencing, of features presented in each of the narratives, can facilitate our decision toward a critically pluralistic environmental aesthetic.

\section{Returning to the Aesthetics of Burning: Examples from North America and Africa}

As the previous examples from Aboriginal Australia suggest, the use of fire to maintain preferable habitat conditions and stimulate vital plant and animal resources has been a common practice in many indigenous societies [22]. Although the reasons for initiating the firing of landscapes vary broadlydriving game, improving visibility, promoting ease of travel, driving away noxious pests like mosquitoes, increasing the supply of food plants, maintaining habitat for game species, fire-proofing villages, and as defensive or aggressive measures in warfare-a common denominator of burning practices across cultures is the role of fire in sustaining a dynamic equilibrium in ecosystem composition [23]. As part of a complex and ecologically specific system of landscape management, traditional burning emerges as a strategy for maximizing subsistence resources. The focus of this section is to examine contemporary and historical documentation of traditional burning regimes from eastern and western North America and Africa with reference to the consequences of each strategy on 
ecosystem structure and to address the diverse stories of burning along the way. As these examples will show, the conscientious selection of certain plant species, the suppression of less important food species, and the subsequent creation of favored habitat for mammals resulted in distinct environments administered on a regular basis by traditional burning.

The indigenous people of the northeastern United States routinely burned the forests and grasslands for many reasons, including the encouragement of plant and animal resources and the clearing of forest understory ([23], p. 334). Journals from the European settlers to the northeastern regions of North America are replete with descriptions of the manicured (i.e., picturesque, a category of aesthetics) appearance of forests, commonly citing traditional burning as the means for clearing forest floor cover. The open quality of the forests impressed early settlers and evoked images of the woodland parks of Europe. As cited by Day, Lindstrom recorded the profusion of tall grass and the trees which "stand far apart, as if they were planted," concluding that the burning of the dry grass for the spring hunt maintained such open conditions ([23], p. 334). Also cited in Day, Morton attributed the tended quality of the woodlands to the "firing of the country" ([23], p. 335) and Johnson observed that the woods were made "thin of timber in many places, like our parks in England" through frequent burning ([23], p. 334). The colonial aesthetic narratives of the landscapes created through the burning regimes of indigenous North American peoples reflect those in Australia around the same time, as previously discussed in Section 4.

Grasslands and open oak forests dominated the plant communities of present-day New York and New Jersey with the distinct "oak openings” characterizing the vegetation pattern ([23], p. 338). The journals of settlers emphasize the openness of the upland woods, detailing oak, chestnut, and hickory communities on the slopes, white pine and hemlock in the swamps, and bushy plains and blueberry barrens on the plateaus and hilltops ([23], p. 337). Russell describes how good timber could only be found in the lowlands since periodic burning of the uplands prevented big trees from maturing [24]. After traditional fire management ceased, pine species began to encroach upon the oak-chestnut communities, and the oak openings diminished as the growth of shrubs went unimpeded ([23], p. 338).

In the woodlands of eastern North America, the frequency of fires affected the forest composition, depending on the intensity of the burn and the vegetation structure before the fire ([24], p. 86). Recent studies of the effects of fire on oak regeneration suggest that occasional light fire may improve oak re-growth for some species while more frequent fires destroy trees ([24], p. 86). Thus, less frequent burns of low intensity probably contributed to the oak communities observed from southern Maine to Virginia in pre-colonial historical documents ([24], p. 86). Furthermore, grass seems to have been the ground cover where there were documented fires, as in present-day New York and New Jersey, indicating that only some places were burned at close intervals ([24], p. 86).

In western North America, fire regimes were also utilized to affect ecosystem structure and to enhance the availability of food species. Turner describes that, apart from the increase in plant productivity, indigenous peoples of western North America understood that landscape burning resulted in enhanced forage for deer and other game ([22], p. 200). In all, at least nineteen species of plants, "including eleven fruiting shrubs, one herbaceous fruit (strawberry) and seven herbaceous 'edible root' species, have been identified by various sources as having their production enhanced by periodic burning” ([22], p. 188). All of the species indicated by Aboriginal peoples of western North America to benefit from periodic landscape burning have the capability to regenerate from buried rhizomes or 
subterranean storage organs and are successional plants ([22], p. 201). However, as bushes encroached on the hills after the cessation of yearly burning, ripe berries vanished and roots like "potatoes" (Erythronium, Lilium columbianum, and Claytonia lanceolata) disappeared ([22], p. 189).

Indigenous people's firing of the land promoted the growth and range of preferred resource species. For instance, the Kalapuya of the Willamette Valley in Oregon burned hazelnut (Corylus cornuta), an early fire follower that flourishes on charred sites ([22], p. 192). Burning the mountainsides promoted the growth of onions (Allium cernuum), raspberries (Rubus idaeus), blackcaps (Rubus leucodermis), and probably huckleberries (Vaccinium membranaceum) ([22], p. 199). There is persuasive evidence for traditional landscape burning of blue camas (Camassia quamash and C. leichtinii) prairies in western Washington and large-scale burning by Aboriginal peoples on Whidbey Island, Washington ([22], p. 195). Alaska blueberries (Vaccinium alaskaense), red huckleberries (V. parvifolium), and salal berries (Gaultheria shallon) also respond especially well after an area has been fired ([22], p. 198). Additionally, evidence clearly indicates that burning influenced the range of certain species. The Tsolum River area of British Columbia is the northernmost location for garry oak (Quercus garryana); because, unlike other garry oak sites, it falls within the Western Hemlock Biogeoclimatic Zone, Page asserts that these oaklands were maintained in the past by periodic burning ([22], p. 197).

The persistent need for young plant growth provoked indigenous western North Americans to periodically carry out the burning of sites for the enhancement of basketry materials. Long straight shoots with no lateral branches that emerge after a section has been burned over were preferred for the manufacturing of many products: "The most favored shrubs, grasses, ferns, and sedges for basketry, as well as the preferred herbaceous plants for edible corms, bulbs, and tubers, all evolved and thrived in a context of periodic disturbances that included flooding, rodent activity, fire, and herbivory” [25]. For example, the Karok and Wiyot burned to make hazel (Corylus cornuta) and willows (Salix spp.) yield superior materials for manufacturing baskets ([25], p. 163). Also, deer grass (Muhlenbergia rigens) was managed with fire to augment flower stalk yield and to bolster the dimensions of the culms ([25], p. 174).

This article began by citing the image of the railroad line delineating forest to one side and prairie to the other in northern Alberta. An analogous scenario is found in Second Nature, where in a village near the Prefecture of Kissidougou in Guinea, the researchers stand at the abrupt edge between the fired savanna and the maturing forest [26]. On a broader level, the forest-savannah transition zone of Guinea is the interface between the equatorial rainforest to the north and the arid lands to the south. The people of Kissidougou employ fire to manage this dynamic zone and, in doing so, increase the fertility of the soil, the abundance of plant resources, and the safety and comfort of their villages. For the Dene, the winter collection of rabbits is augmented by spring burning; by inducing early growth or early succession of plants during the spring burn, the plants achieve more robust growth to fortify them through the winter and make available plant nutrients to foragers. Similarly, for the people of Kissidougou, a regime of burning constitutes a seasonal resource management technique. Burning is strategic in both cultures. The ecological premises underlying Kissidougou decisions to initiate a burn are as equally complex for the Dene. For example, the Kissidougou firers balance between white grass and long grass, cognizant of how a predominantly long grass environment will transition to forest whereas a white grass savannah will not. Thus, the choice to facilitate forest growth functions with the management of savannah grasses. 
The firing strategies of both cultures maintained a dynamic balance between grassland and forest. The major distinction, however, between the northern Dene and Kissidougou systems of burning is that the Dene strategy aimed to maintain the grassland prairies of northern Alberta's boreal forest while the firing system of the people of Kissidougou encourages productive forest rings around the villages. The cessation of Dene burning has resulted in the encroachment of forest, obscuring once long-spanning views over the rivers of the land as related by the elders. By contrast, the modern increase in Kissidougou burning, as part of a comprehensive ecosystem management scheme, has resulted in the deliberate encircling of villages by forests where savannah dominated even fifty years prior. Other differences between the systems include the plant species involved; the Dene once actively managed an aspen, birch, and willow parkland whereas the Kissidougou forests are mostly red oil palms, coffee trees, kola, and silk cotton trees. And whilst there are clear ecological effects in their fire management practices, there are also aesthetic effects that these particular narratives suggest.

\section{Narratives of Fire and Ice in Dialogue: Representing the Natural World in Critically Pluralistic Terms}

This article has examined a sampling of the diverse narratives that can facilitate our aesthetic regard for the nature of fire and ice, savannah and mountain. Carlson's model claims the narrative of science as the most appropriate one. However, we have seen, using Denali and the burning practices of indigenous peoples across the world as examples, that appropriate (i.e., broad based and culturally diverse) aesthetic responses can be derived from indigenous and journalistic accounts as equally and effectively as scientific discourses, particularly evidenced by the discussion of firing practices in different cultures as observed by “outsiders” and expressed by “insiders.” Whether we give credence to the subduction of tectonic plates or the crystallization of enormous waves agitated by the treachery of Raven should not matter. The aesthetic experience proffered by both-the symphony of abrasion, slipping, scuffing, and sculpting arranged by astounding geological forces adhering to a nearly incomprehensible standard of time; the elegant transfer of energy and form from the wave of a lake to the crest of the mountain; an exchange roused by the misdeeds of a personified raven; or an aesthetic sense for country as clean and cared for-convey the distinctive essence of a landscape, prompting a sensible aesthetic response to these places, hence revealing them in written terms, increasingly, for what they are. Furthermore, journalistic accounts, though inherently combining subjective and objective impressions, present a story of the natural world from which we can derive aesthetic values. Whether our aesthetic appreciation is a misguided or accurate one depends on the sources of aesthetic information we engage with. Our appreciation of nature can become critically aesthetic without turning toward monolithic notions of truth and essentialist science.

I have argued that diverse narrative forms-science, indigenous cosmologies and knowledge, and journalistic accounts - can provide equally substantial representation of aesthetic qualities. The aesthetic subject might be satisfied to consider the harmoniously separate existence of such narratives, each artfully employed by the groups (scientists, indigenous groups, and journalists) who promulgate them. Let the geologists have their fill of tectonics and the tediously slow movement of landmass; indigenous peoples their fascination for Raven, the spontaneous generation of landscape protrusions in their Dreaming stories, or their ecocultural narratives of fire; the explorer his personal version sketched 
from a single instance of exposure to the vicissitudes of the mountain and filtered through written language in historical documents. The "two cultures" gulf subsides when we invite narrative forms to keep each other in line; and to verify the degree to which the other makes appreciable the real aesthetic properties of a specific natural feature embedded in a distinct ecology and cultural milieu. I assert that this "cross-checking” of aesthetic narratives offers a sensitive yet critical reflection of the natural world as an ecocultural creation. Holmes Rolston states: "Metaphysical fancy has to be checked by a pragmatic functioning, and this includes an operational aesthetic with some successful reference to what is there at one’s location” ([11], p. 383). Unlike Rolston who implies a hierarchy, I maintain that each narrative should bear weight in a critically pluralistic environmental aesthetic. Accordingly, scientific narrative need not overshadow the cosmologies and practices of indigenous peoples. Stories of consensus, those shared by groups of people and generations as cultural works (science and mythology), verified by their antiquity or the "test of time," should not supersede the obviously subjective representations of the natural world in past and present journalistic accounts.

Returning to a critically pluralistic aesthetic of Denali as an example, the assertions of geology - the uplift of plates and the eroding action of glaciers-would be understood only in reference to the eye-witness stories of explorers. Conversely, the explorers' accounts could bear witness to the talus jumble and the glacial sheets, confirmed by geology's rationalization of the same talus. Furthermore, indigenous knowledge would confirm the unique perceptual features of the mountain summit, the semblance of a frozen wave, which in turn is confirmed by first-hand personal exposition and scientific explanation of Denali's glaciation and high-altitude wind patterns. This process, which I call "cross-checking," involves discerning aesthetic realities, passing multiple accounts through the sieve of human perception to separate the most developed, established, and nuanced narratives from mere idiosyncratic flights of fancy that do not represent nature in its own terms, acceptably. Particularly with the advent of digital media during the last twenty years, individuals access multiple environmental narratives sequentially or on a one-by-one basis according to their interests, locations, or practices at any given time. Hence, there is a multitude of ways people access and interpret narratives; and thus a need for a philosophy of environmental narrative heterogeneity to guide individuals in their assessments.

Concerns endemic to "the story"-for instance, multiple acceptable interpretations; the anthropocentric humanizing of nature; and the representation of the natural world through a cultural bias - can be addressed when each narrative is critically examined against another, rather than through its internal logic, as with scientific narratives in particular. Through cross-checking, geological narratives would help to illuminate cosmological stories, which might reciprocally illuminate journalistic accounts in order to distill appreciable aesthetic qualities into an integrated whole. As such, the wave-like patterns of snow atop Denali are identifiable in all three narratives. Aesthetic exaggerations - those isolated and possibly distorted representations of nature (Denali's slopes flanked in gold sheets!)—-would be immediately identified as anomalous and possibly dispelled or further investigated. In this manner, our fanciful projections upon the natural world would be kept in check without dismissing imagination - that significant human dimension of experience of the environment, often marginalized in light of Cartesian objectivity or Kantian disinterestedness. Where multiple stories mutually illuminate one another, we find a narrative environmental aesthetic that represents nature to the most inclusive degree possible by integrating elements of diverse stories: scientific, indigenous, and journalistic as the three selected for this article. 


\section{Conclusion: Toward Critical Pluralism through Narratives}

An environmental aesthetic philosophy based upon multiple narratives of nature is embryonic in part because narrative is regarded as a minor element of environmental aesthetics. Cross-checking constrains our interpretations of the stories of nature, enhancing and grounding our appreciation by filtering away narratives that are probably not representative of nature and therefore not appropriate. Science, indigenous cosmologies and practices, and journalistic accounts constitute a larger story, a dynamic and integrated history. I argue that stories are part of a holistic environmental aesthetic that draws from human and non-human emotions, moods, and imaginings. A narrative natural aesthetic can be one of critical pluralism. Emily Brady writes that "critical pluralism sits between critical monism and 'anything goes,' the subjective approach of some post-modern positions. It argues for a set of interpretations that are deemed acceptable but which are not determined according to being true or false... An interpretation must be acceptable, it cannot be outlandish, irrelevant or the whim of one person” [27]. In terms of the general moral derived from the case studies of snow and fire, I align with Brady's “critical pluralist” approach which argues for the acceptability of aesthetic interpretations rather than the determination of truth or falsehood amongst them. Hence, the environmental aesthetic syncretically derived from scientific, indigenous, and journalistic perspectives is not based on polarized value judgments — which could demarcate and set in opposition those perspectives - but rather on their points of intersection. The mechanism of "cross-referencing," which seeks commonalities and nodes of connection, facilitates the assessment of acceptability along a continuum from "outlandish" and "irrelevant" to appropriate for certain environments and acceptable to the well-being of the human and more-than-human life residing there.

Through critical pluralism, “cognitive” aesthetic theories, such as Carlson's natural environmental model, and "non-cognitive" approaches, based in imagination and mythologies, dynamically co-exist, amplifying one another to represent nature on its own terms. An integrated environmental aesthetic benefits from the complementarity of different narratives and aesthetic modes. Indeed, "non-cognitive" modes, represented by human imagination, moods, and emotions, provide important components deficient in scientific narrative approaches yet crucially important to human appreciation of nature. Indeed, as feminist philosophical work argues, the non-cognitive (subjective, imaginative, intuitive, emotional) and cognitive (objective, rational, logical, deductive) binary is an assumption that plagues much ethical theory. Rather than conceptualizing subjective, imaginative, and poetic interpretations of reality as either true or false (and thus reverting to traditionally "cognitive” criteria), a critically pluralistic aesthetic draws from Brady's notion of acceptability as the interpenetration of the "cognitive" and "non-cognitive" in any form of aesthetic experience of the natural world [28]. Simply put, one mode of experiencing and/or representing nature narratively should not come at the expense of another. A critically pluralistic environmental aesthetic would draw from all of our senses, our intellect, and our personal proclivities. Importantly, as David Sobel has observed, "environmental empathy" develops from experience and imagination as "a feeling for other creatures that can develop into a willingness to care for other creatures" [29]. Sobel argues that empathy establishes the groundwork for learning ecological science later in life. As I have tried to demonstrate through the stories of Denali and those of indigenous firing practices, a productive and critical tension between all modes of narrative ensures that nature is appreciated and valued appropriately. The articulation of 
narrative heterogeneity in the formation of a critically pluralistic environmental aesthetic - where diverse expressions of nature mutually illuminate one another-should be the subject of further considerations. This is especially urgent because, as I sit here writing in January 2013, a constellation of blazes-amplified by temperatures above 100 degree Fahrenheit, powerful winds, and low levels of winter rain - threaten many parts of Tasmania, New South Wales, and Victoria in Australia. Undoubtedly in relation to these fires, new narrative forms will surface in the media-the complaints of residents against emergency services agencies; the stories of locals who have lost their homes; memories of these catastrophes in relation to other catastrophes from other years; the reminders of scientists who attribute more intense fires to climate change; and the wisdom of Aboriginal peoples who maintained small-scale fire regimes in Australia for over 40,000 years. One of the challenges of our age is to encompass these diverse narratives - ever vigilant for their aesthetic, sensory, and bodily implications for human and more-than-human well-being - into integrated forms of knowing, being, and co-existing.

\section{Acknowledgments}

The author thanks the University of Lancaster (UK) and Edith Cowan University (Australia) for their support during this research.

\section{References}

1. Henry Lewis. Fires of Spring. Alberta, Canada: University of Alberta, 1978. Film, 32 minutes.

2. Ian Lunt, and John Morgan. "The Role of Fire Regimes in Temperate Lowland Grasslands of South-Eastern Australia.” In A Flammable Australia: The Fire Regimes and Biodiversity of a Continent. Edited by Ross Bradstock, Jann Williams and Malcolm Gill. Cambridge, UK: Cambridge University Press, 2002, 177-98.

3. Henry Lewis. "Traditional Uses of Fire by Indians in Northern Alberta.” Current Anthropology 19, no. 2 (1978): 401-02.

4. Deborah Bird Rose. Nourishing Terrains: Australian Aboriginal Views of Landscape and Wilderness. Canberra, Australia: Australian Heritage Commission, 1996, 65.

5. Susan Schwartz. "Lecture 19: Alaska Geology and Denali National Park." Available online: http://ic.ucsc.edu/ susans/eart3/Lectures/lecture20.html (accessed on 5 November 2011).

6. Allen Carlson. “Appreciating Art and Appreciating Nature.” In Landscape, Natural Beauty and the Arts. Edited by Salim Kemal and Ivan Gaskell. Cambridge, UK: Cambridge University Press, 1993, 199-227.

7. Marcia Eaton. "Fact and Fiction in the Aesthetic Appreciation of Nature." The Journal of Aesthetics and Art Criticism 56, no. 2 (1998): 149-56.

8. Richard Nelson. Make Prayers to the Raven: A Koyukon View of the Northern Forest. Chicago, IL: University of Chicago Press, 1983, 34.

9. Thomas Heyd. “Aesthetic Appreciation and the Many Stories About Nature.” British Journal of Aesthetics 41, no. 2 (2001): 125-37.

10. Eugene Hunn. Nch'i-Wana “The Big River:” Mid-Columbia Indians and Their Land. Seattle, WA: University of Washington Press, 1990, 85. 
11. Holmes Rolston. "Does Aesthetic Appreciation of Landscapes Need To Be Science-Based?" British Journal of Aesthetics 35, no. 4 (1995): 374-85.

12. Yuriko Saito. “Appreciating Nature On Its Own Terms.” Environmental Ethics 20 (1998): 135-49.

13. David Bowman, and Tom Vigilante. "Conflagrations: The Culture, Ecology, and Politics of Landscape Burning in the Northern Kimberley.” Ngoonjook 20 (2001): 38-45.

14. D. Yibarbuk, P.J. Whitehead, J. Russell-Smith, D. Jackson, D. Godjuwa1, A. Fisher, P. Cooke, D. Choquenot, and D.M.J.S. Bowman. "Fire Ecology and Aboriginal Land Management in Central Arnhem Land, Northern Australia: A Tradition of Ecosystem Management.” Journal of Biogeography 28 (2001): 325-43.

15. Jeremy Russell-Smith. "Indigenous Fire Practice in Western Arnheim Land: Lessons for Today.” Available online: http://www.savanna.cdu.edu.au/downloads/indfire.pdf (accessed on 19 February 2013).

16. Henry Lewis. "Ecological and Technological Knowledge of Fire: Aborigines Versus Park Rangers in Northern Australia.” American Anthropologist 91, no. 4 (1989): 940-61.

17. Sylvia Hallam. "Plant Usage and Management in Southwest Australian Aboriginal Societies.” In Foraging and Farming: The Evolution of Plant Exploitation. Edited by David Harris and Gordon Hillman. London, UK: Unwin Hyman, 1989, 136-51.

18. Jon Marsden-Smedley. "Fire Management in Tasmania's Wilderness World Heritage Area: Ecosystem Restoration Using Indigenous-Style Regime Fires?” Ecological Management \& Restoration 1, no. 3 (2000): 195-203.

19. Deborah Bird Rose. Dingo Makes Us Human: Life and Land in an Aboriginal Culture. Cambridge, UK: Cambridge University Press, 1992, 100-01.

20. Fred Beckey. Mount McKinley: Icy Crown of North America. Seattle, WA: Mountaineers, 1993, 61.

21. Yi-Fu Tuan. "Desert and Ice: Ambivalent Aesthetics.” In Landscape, Natural Beauty and the Arts. Edited by Salim Kemal and Ivan Gaskell. Cambridge, UK: Cambridge University Press, 1993, 139-57.

22. Nancy Turner. “'Time To Burn': Traditional Use of Fire To Enhance Resource Production by Aboriginal Peoples in British Columbia.” In Indians, Fire, and the Land in the Pacific Northwest. Edited by Robert Boyd. Corvallis, OR: Oregon State University Press, 1999, 185-218.

23. Gordon Day. "The Indian as an Ecological Factor in the Northeastern Forest.” Ecology 34, no. 2 (1953): 329-46.

24. Emily Russell. "Indian-Set Fires in the Forests of the Northeastern United States.” Ecology 64, no. 1 (1983): 78-88.

25. Kat Anderson. "Native Californians as Ancient and Contemporary Cultivators." In Before the Wilderness: Environmental Management by Native Californians. Edited by Thomas Blackburn and Kat Anderson. Menlo Park, CA: Ballena Press, 1993, 151-74.

26. Graham Maughan. Second Nature: Building Forests in West Africa's Savannas. Haywards Heath, West Sussex, UK: Cyrus Productions, 1996. Video, 41 minutes.

27. Emily Brady. Aesthetics of the Natural Environment. Edinburgh, Scotland: Edinburgh University Press, 2003. 
28. Helen Longino. “Cognitive and Non-Cognitive Values in Science: Rethinking the Dichotomy.” In Feminism, Science, and the Philosophy of Science. Edited by Lynn Hankinson Nelson. Dordrecht, The Netherlands: Kluwer Academic Publishers, 1997, 39-58.

29. David Sobel. Childhood and Nature: Design Principles for Educators. Portland, ME: Stenhouse Publishers, 2008, 30.

(C) 2013 by the author; licensee MDPI, Basel, Switzerland. This article is an open access article distributed under the terms and conditions of the Creative Commons Attribution license (http://creativecommons.org/licenses/by/3.0/). 